\title{
An Analysis of Rainfall Characteristics in Machakos County, Kenya
}

\author{
Julius M. Huho \\ (Arts and Social Sciences, Garissa University College, Kenya)
}

\begin{abstract}
Rain-fed agriculture accounts for about 60\% of global and 90\% for Sub-Saharan African (SSA) staple food production. Over $80 \%$ of the population in SSA depends on rain-fed agriculture as their livelihood source. Rainfall performance is therefore crucial in socio-economic development of the agri-based economies. This study sought to analyze rainfall characteristics in Machakos County, Kenya where the inhabitants are largely agriculturalists. Rainfall data was obtained from KARI Katumani and Mutisya Mango Farm rainfall stations and analyzed using various climatological statistics. Rainfall was of moderate distribution being concentrated in approximately $75 \%$ of the years/seasons. Normal and wet conditions dominated the climate with droughts occurring once in every 4 years. Drought frequency was higher during the long (March, April and May) and the short (October, November and December) rains occurring once in every 3 years, causing food insecurity in the County. Negative rainfall trend and higher rainfall variability in Mutisya Mango Farm stations made rainfall less dependable compared to KARI Katumani which had lower rainfall variations. It was therefore easy to use the rainfall mean to predict rainfall performance and to plan agricultural activities in KARI Katumani. Variation in rainfall amount during the wet and normal climatic conditions was identified as the key rainfall parameter influencing rain-fed agriculture activities in Machakos County.
\end{abstract}

Keywords: Exceedance probability, Rainfall distribution, Rainfall variations, Trend analysis

\section{Introduction}

Rainfall is the most important climatic element in Sub-Saharan Africa (SSA). Essentially, rainfall controls agriculture which is the mainstay of SSA economies and the predominant source of rural livelihoods. Agricultural production is dependent on rainfall performance. Approximately $80 \%$ of the SSA population is smallholder farmers living in rural areas and dependent on rain-fed agriculture as livelihood source. In addition, about $10 \%$ to $25 \%$ of the urban dwellers depend on agriculture as their livelihood source [1]. However, rainfall exhibits varying characteristics resulting in normal, above or below normal rainfall. For instance, [2] observes that the year 2013 received normal rainfall based on the 1961-1990 long-term rainfall mean of 1033mm. In eastern Africa however, the March - April 2013 season received above normal rainfall that led to heavy flooding. In Malaysia, [3] observed increasing annual totals but with very high monthly variation ranging from $30 \%$ to $+30 \%$. Episodes of repeatedly delayed rainfall onset, short dry spells and prolonged droughts have been experienced in Nigeria over the last 60 years [4]. In the Horn of Africa, decline in the long rains (March, April and May) in the past 30 years resulting in below normal rainfall have been observed [5]. This has had a major impact on the regions' food security. A study in Laikipia East Sub County of Laikipia County by [6] revealed a decrease in number of rain days and an increase in rainfall intensity. Understanding these varying rainfall characteristic is crucial in planning since they play constructive or destructive roles in livelihood sources.

\section{Objective Of The Study}

The study aimed at analyzing rainfall characteristics in Machakos County in order to understand the County's rainfall performance. Livelihood sources of the majority of the inhabitants in the County are dependent on rainfall performance.

\section{Methodology}

The key variable for the study was rainfall. Two rainfall data sets were obtained from two stations in Machakos County namely KARI Katumani and Mutisya Mango Farm rainfall stations. Machakos County is located in Eastern Kenya (S 01 ${ }^{\circ} 34.56$, E $037^{\circ} 14.43$ ). It has an elevation ranging from 400 to 2100 meters above sea level and falls under the semi-arid to arid climates. KARI Katumani station is located on low and rolling areas of the County while Mutisya Mango Farm Station is located in the hilly areas in Katheka Kai Sub Location of the Machakos County. Agriculture is the main source of livelihood for the majority of the population in the County. Rainfall data was used to compute annual and monthly totals, seasonal and annual distribution, seasonal and annual variations, rainfall concentration, time series analysis and probability exceedance. The following methods were used to establish various rainfall characteristics: Precipitation Concentration index (PCI) for annual and seasonal rainfall concentration; coefficient of variation $(C V)$ for 
variations in annual and seasonal rainfall and the Mann-Kendall (MK) trend test for trend analysis. Addinsoft's XLSTAT Software was used to calculate the statistical Mann-Kendall test. The null hypothesis $\left(\mathrm{H}_{0}\right)$ was tested at $95 \%$ confidence level.

\section{Results And Discussion}

\subsection{Annual and Seasonal Rainfall Distribution}

Rainfall data for 25 years $(1990$ - 2014) was obtained from KARI Katumani and Mutisya Mango Farm rainfall stations in Machakos County. Rainfall was higher in KARI Katumani with a long term mean of $730.1 \mathrm{~mm}$ compared to Mutisya Mango Farm station which had a long term mean of $611 \mathrm{~mm}$. Each of the two stations had two rainfall seasons, the short and the long rains. The long rainfall season occurs from March to May while the short rain season occurs from October to December. The two rainfall seasons are separated by a dry spell between June and September (Fig 1 and 2).
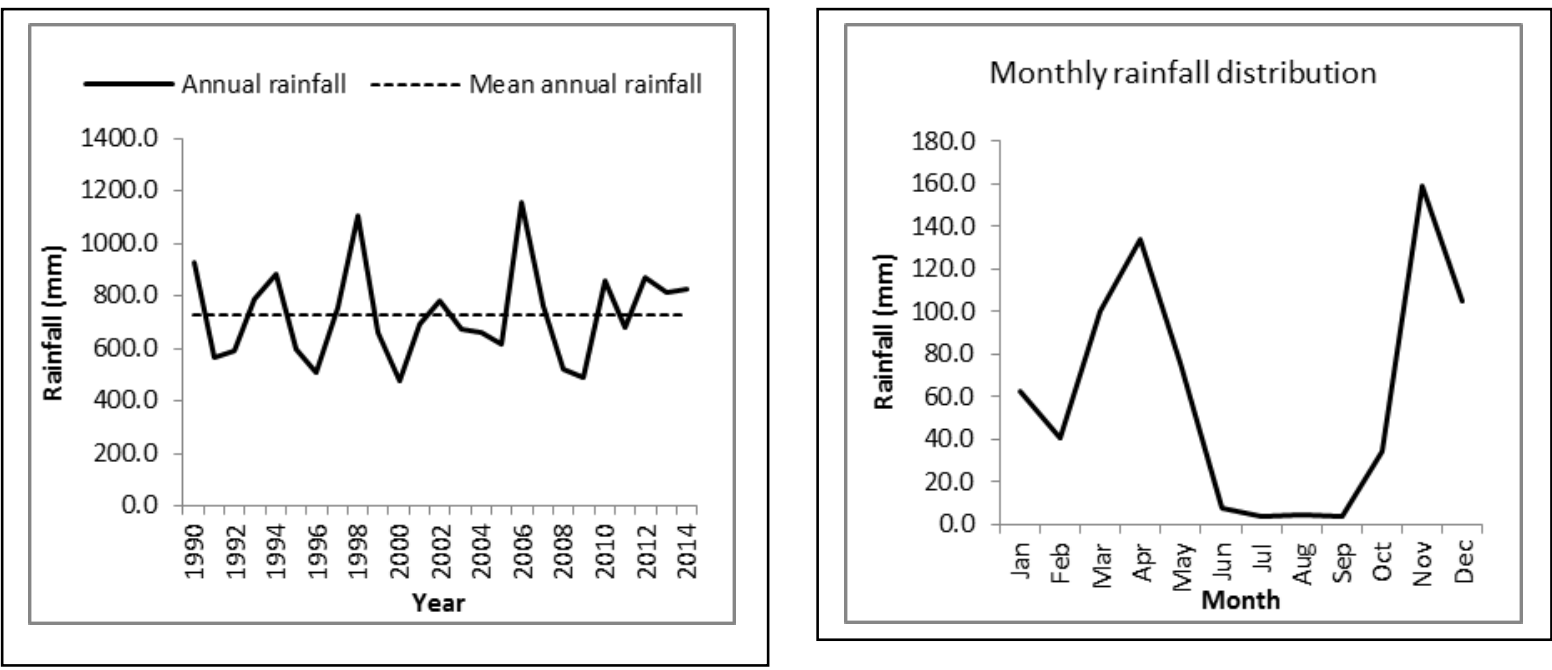

Figure: 1: Annual and monthly rainfall distribution at KARI Katumani station
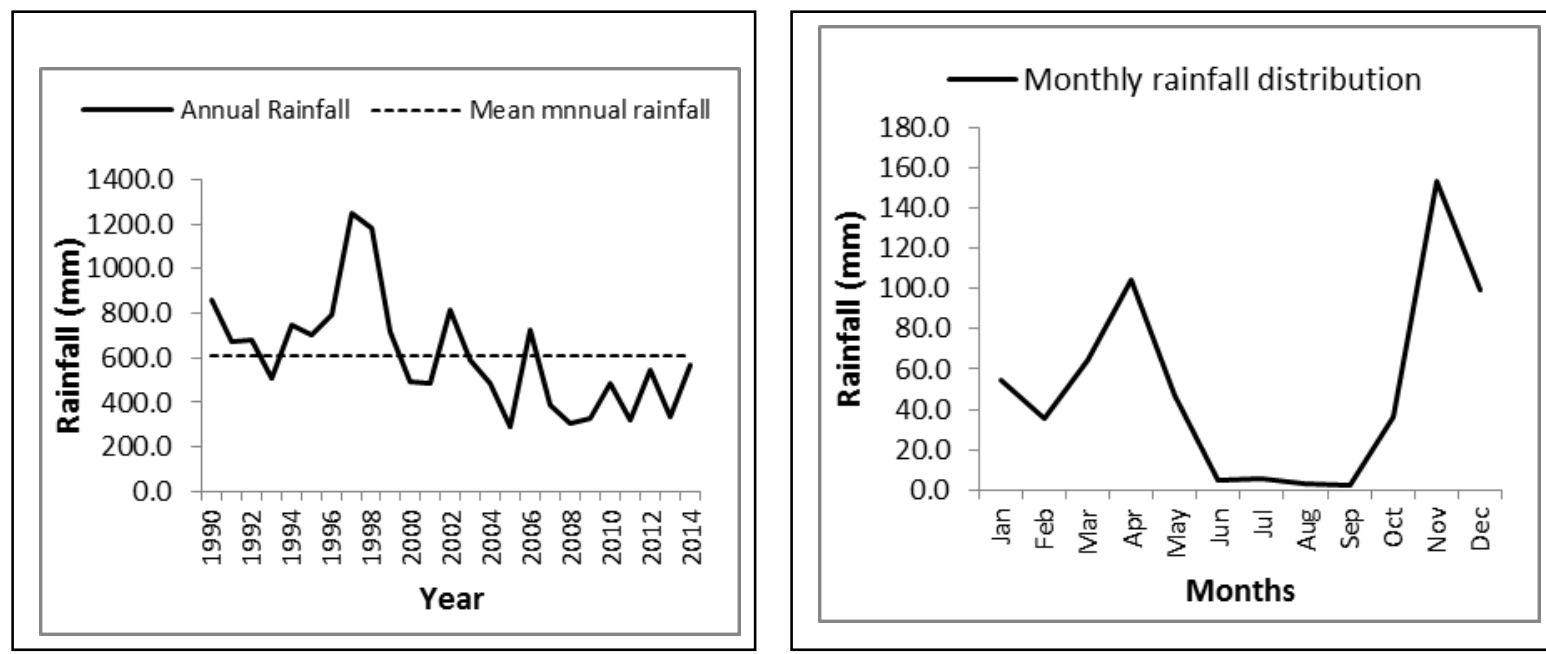

Figure 2: Annual and monthly rainfall distribution at Mutisya Mango Farm station

Seasonal distribution of rainfall is very important for Machakos County since the inhabitants depend on rainfall performance for sustained livelihood source. Farmers grow crops when rainfall peaks in March, April and May (MAM) and in October, November and December (OND). The primary (main) crop growing season is OND since the short rainy seasons are more reliable. The MAM rains support secondary crop growing season. On average, KARI Katumani station receives about $309.9 \mathrm{~mm}$ and $298 \mathrm{~mm}$ of rain during the MAM and OND seasons while Mutisya Mango Farm station receives $215.7 \mathrm{~mm}$ and $288.7 \mathrm{~mm}$ during the two seasons respectively (Fig 3 and 4). 

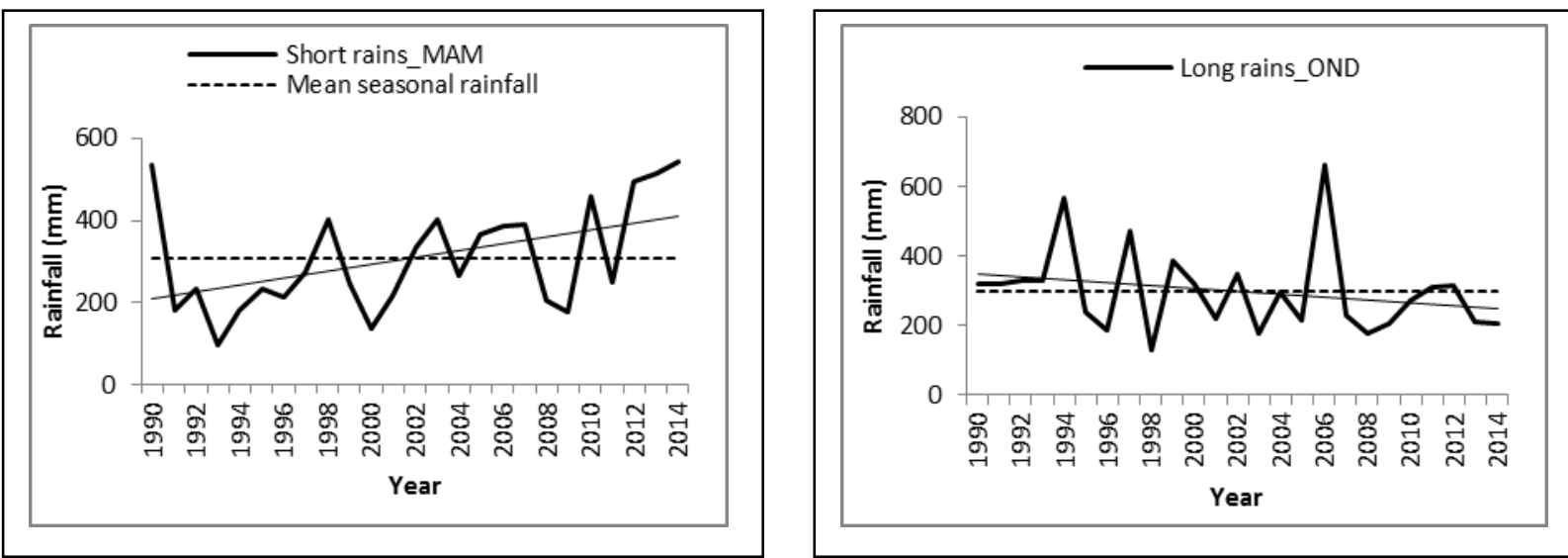

Figure 3: Seasonal rainfall distribution at KARI Katumani station
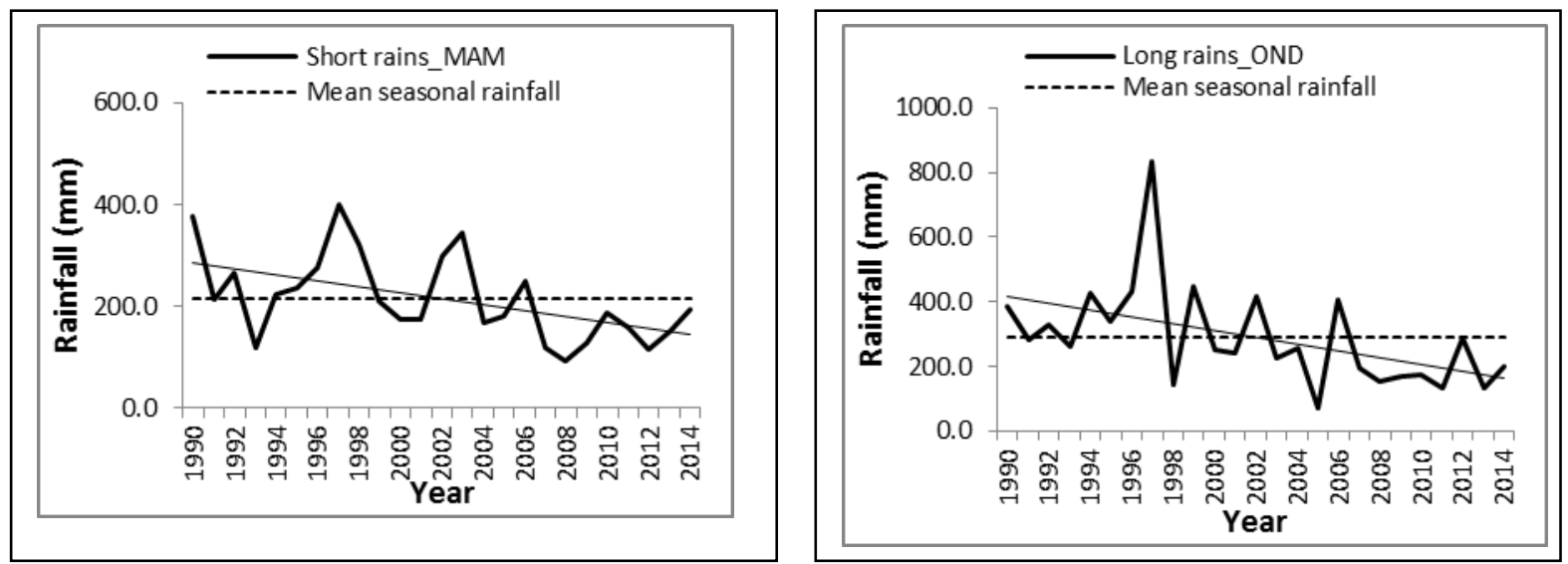

Fig 4: Seasonal rainfall distribution at Mutisya Mango Farm station

During the MAM season rainfall amount ranged from $95.4 \mathrm{~mm}$ to $545.2 \mathrm{~mm}$ in KARI Katumani and from $93.9 \mathrm{~mm}$ to $399 \mathrm{~mm}$ in Mutisya Mango Farm. In the OND season, rainfall amount ranged from $129.7 \mathrm{~mm}$ to 600.4 and from $74 \mathrm{~mm}$ to $834 \mathrm{~mm}$ in the two stations respectively.

Precipitation Concentration Index (PCI) was used to establish the degree in which rainfall is concentrated within a year and within seasons hence the distribution. Concentration of rainfall was established using annual and seasonal PCI as shown in the equations below.

$$
\begin{aligned}
P C I_{\text {annual }} & =\frac{\sum_{i=1}^{12} P_{i}^{2}}{\left(\sum_{i=1}^{12} P_{i}\right)^{2}} * \\
P C I_{\text {Seasonal }} & =\frac{\sum_{i=1}^{3} P_{i}^{2}}{\left(\sum_{i=1}^{3} P_{i}\right)^{2}} * 25
\end{aligned}
$$

Where PCI $=$ Precipitation Concentration Index and $\mathrm{P}=$ precipitation

According to [7] PCI classification, uniform rainfall distribution occurs when PCI is less than 10, i.e. the precipitation concentration is low. The distribution is moderate when the value ranges from 11 to 15 , irregular distribution from 16 to 20 and strong irregularity when PCI values are greater than 20. A higher PCI value implies that precipitation is concentrates in a few number of days in a year/ season and vice versa. The annual rainfall PCI was nearly the same in both stations. KARI Katumani station had a PCI of 14.4 while Mutisya Mango Farm station had a PCI of 15.0. This indicated a moderate distribution where the total rainfall was concentrated in approximately $75 \%$ of the year. Seasonal PCI was established in order to examine the concentration of rainfall during the crop growing seasons. The OND seasons had PCI of 10.5 in KARI Katumani and 10.4 in Mutisya Mango Farm stations. The MAM seasons had PCI of 8.8 and 9.2 for the two 
stations respectively. Comparatively, MAM season had a relatively uniform rainfall distribution $(<10)$ than the OND season (10.5). However, since the OND seasons had higher rainfall totals and the rainfall was concentrated in approximately $75 \%$ of the season, the OND season was more suitable for rain-fed crop farming.

\subsection{Dry, Normal and Wet Years}

Meteorologically, dry and wet climatic conditions occur when rainfall is below and above the longterm mean (normal). Based on this definition, between 1990 - 2014 drought conditions were experienced in $52 \%$ and $56 \%$ of the period under study in KARI Katumani and Mutisya Mango Farm stations respectively. Wet conditions were reported in $48 \%$ and $46 \%$ of the period in the two respective stations. However, cognizance to the fact that a $1 \mathrm{~mm}$ drop in rainfall amount below the long-term mean does not necessarily lead to drought, the study included a period of normal rainfall in its definition. Hence, climatic conditions were categorized as dry (drought), normal and wet. In this study, dry climatic conditions (droughts) were considered to have occurred when rainfall was below two -thirds of standard deviation from the mean $\left(\mathrm{x}^{-}-2 / 3 \delta\right)$, normal when rainfall amount was in-between $x^{-}-2 / 3 \delta$ and $x^{-}+2 / 3 \delta$ and wet when rainfall amount was above $x^{-}+2 / 3 \delta$ (Fig 5 and 6). Normal climatic conditions were the most suitable for rain-fed agriculture. Even with year-to-year and season-to-season rainfall variation farmers required very minimal coping strategies within the normal climatic conditions.

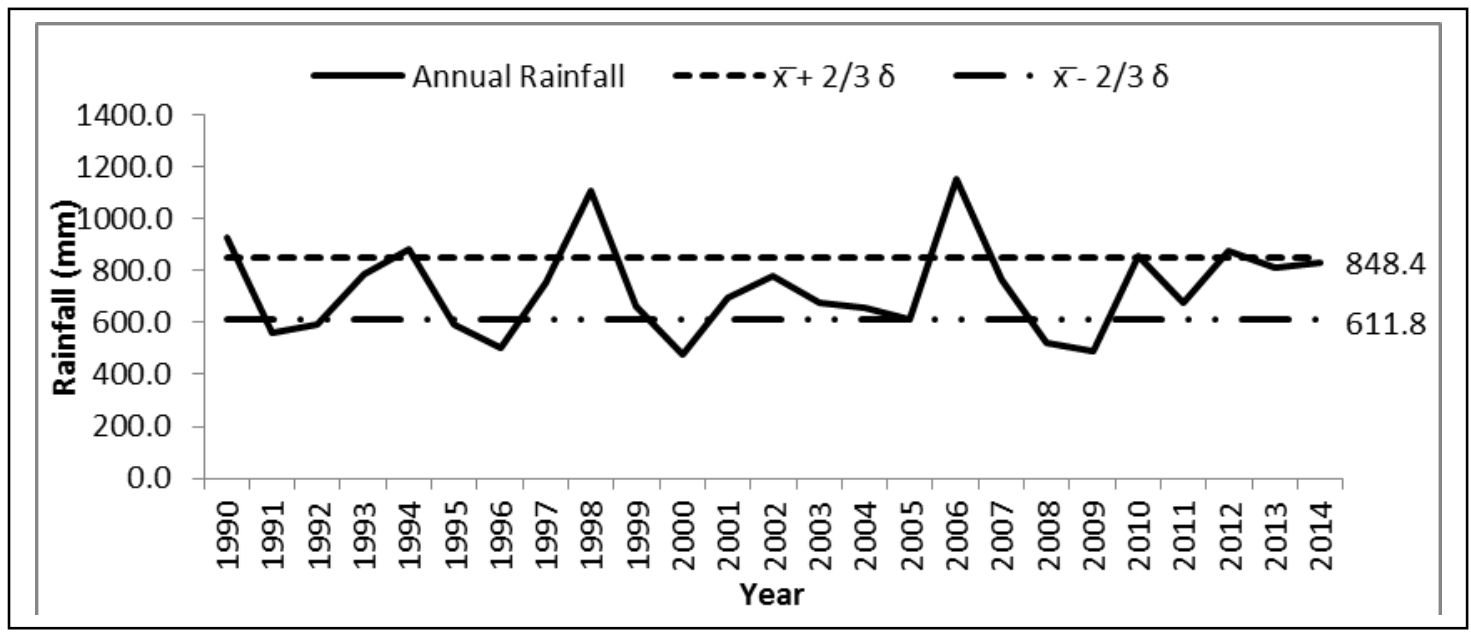

Figure 5: Drought, normal and wet years in KARI Katumani station

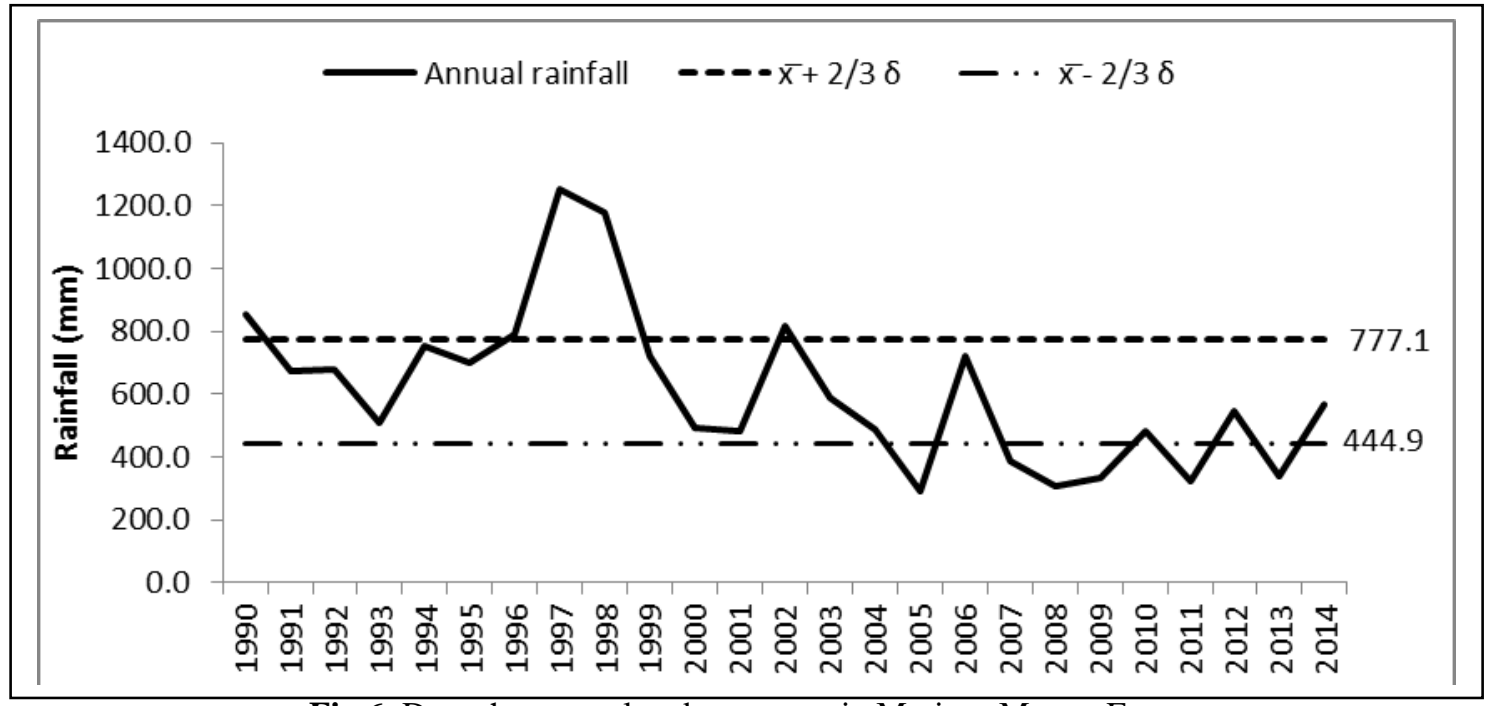

Fig 6: Drought, normal and wet years in Mutisya Mango Farm

Analysis of annual rainfall data in Figures 5 and 6 revealed that normal climatic conditions were more prevalent. Half of the study period (48\% and 56\% in KARI Katumani and Mutisya Mango Farm stations respectively) had normal climatic conditions. Episodes of wet conditions were the least frequent occurring in $24 \%$ and $20 \%$ of the study period in the two rainfall stations respectively. The normal and wet climatic conditions accounted for between $72 \%$ and $76 \%$ of the study period. These conditions were favourable for rain- 
fed agriculture. Drought conditions occurred in $28 \%$ and $24 \%$ of the period under study in the two stations respectively. The County thus experienced a drought cycle of 3 to 4 years impacting negatively on food security.

Seasonal rains were largely characterized by normal climatic conditions. During the MAM season, about $40 \%$ and $52 \%$ of the study period in KARI Katumani and Mutisya Mango Farm stations experienced normal climatic conditions (Fig 7, 8, 9 \& 10).

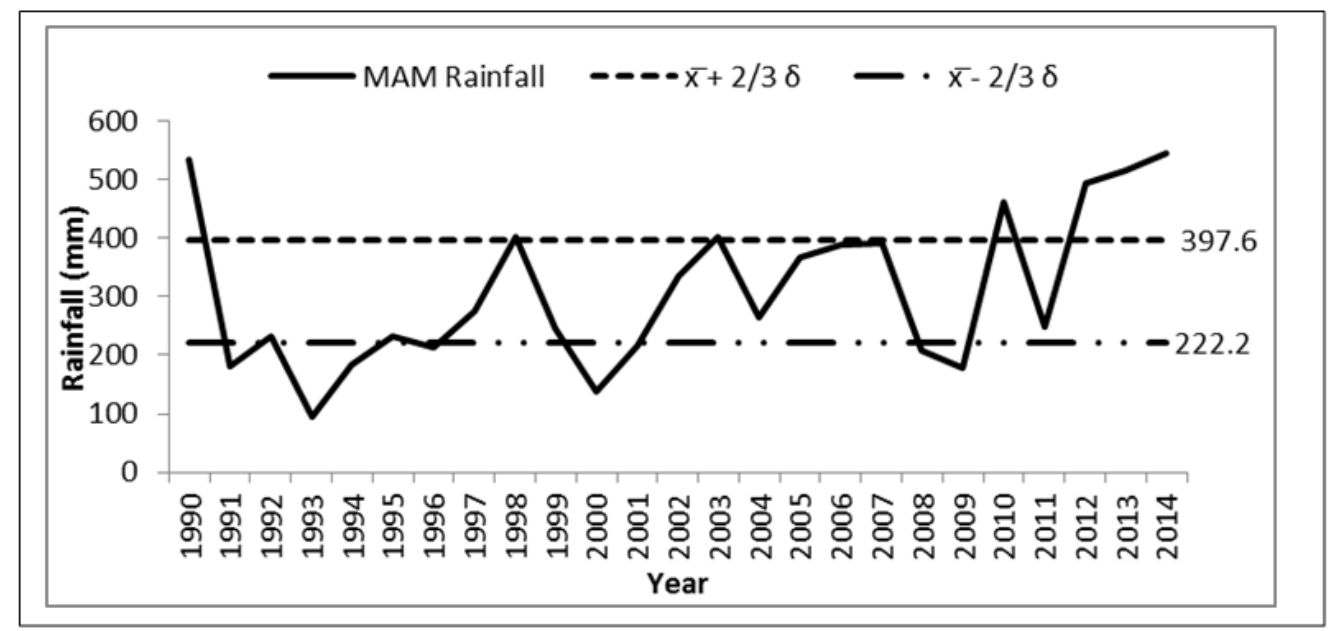

Fig 7: Drought, normal and wet years in KARI Katumani station during the MAM season

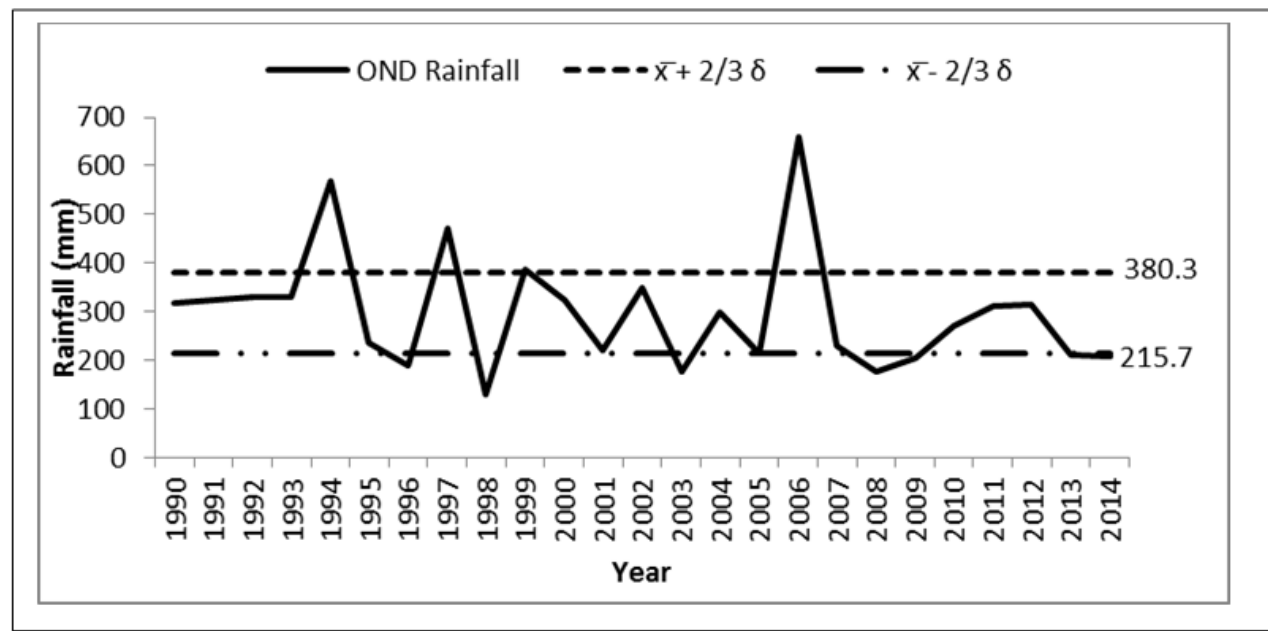

Fig 8: Drought, normal and wet years in KARI Katumani during the OND season

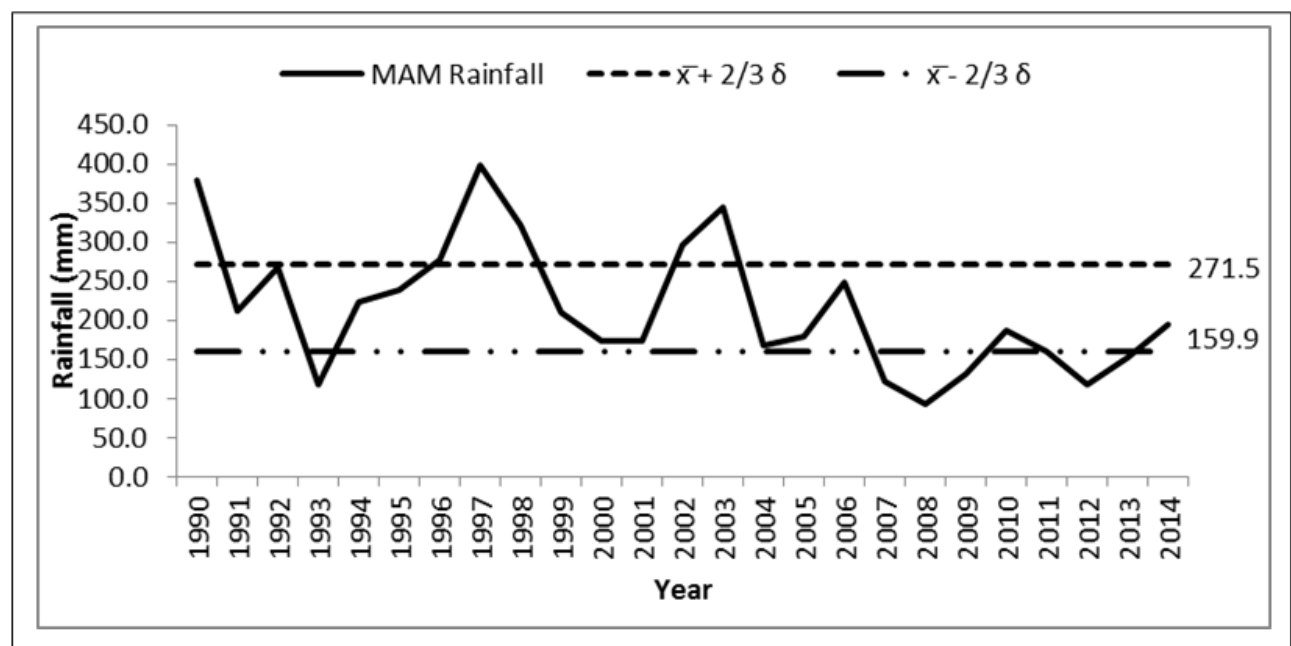

Fig 9: Drought, normal and wet years in Mutisya Mango Farm station during the MAM season 


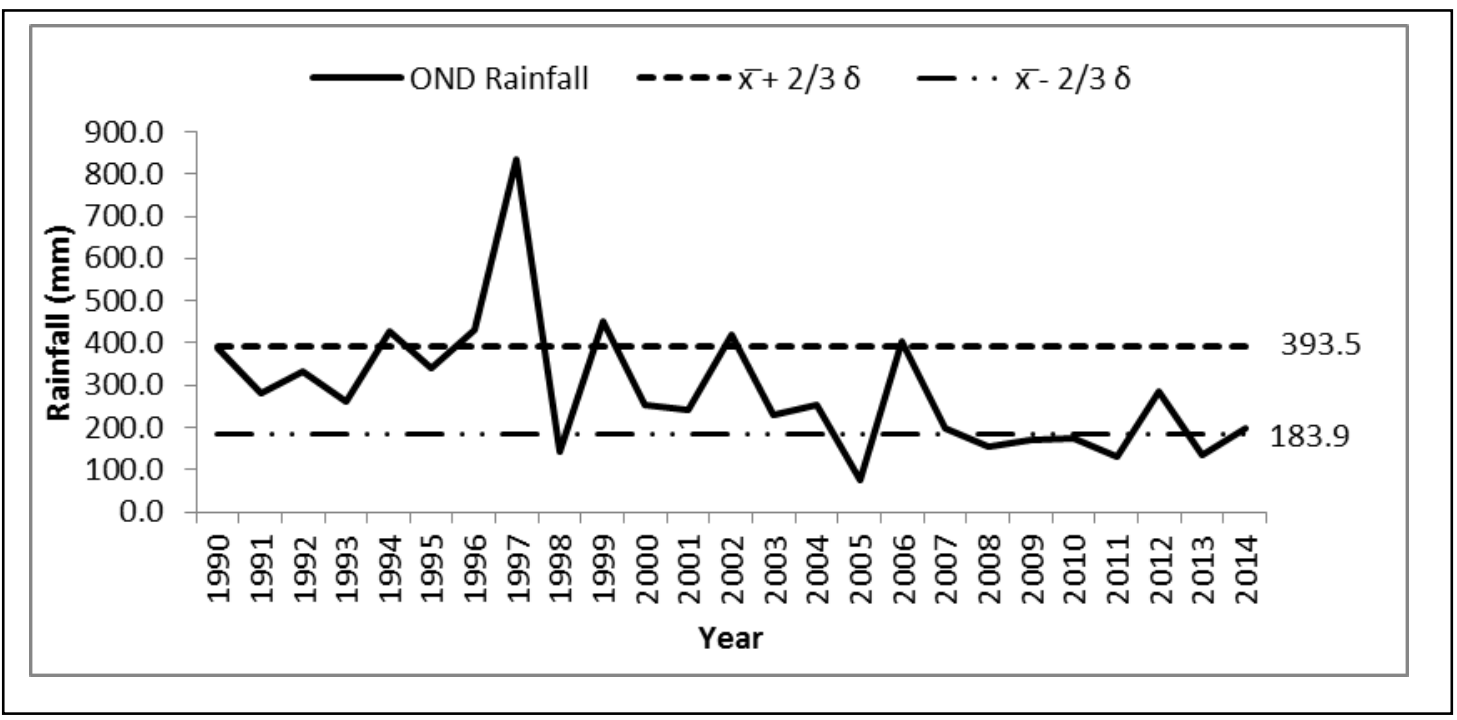

Fig 10: Drought, normal and wet years in Mutisya Mango Farm station during the OND season

During the OND season, $52 \%$ and $48 \%$ of the study period had normal climatic conditions in KARI Katumani and Mutisya Mango Farm stations respectively. Wet climatic conditions were experienced in 28\% and $16 \%$ of the study period in KARI Katumani station during the MAM and OND seasons in that order. In Mutisya Mango Farm station, both MAM and OND seasons each had $24 \%$ of the study period being wet. Dry climatic conditions ranged between $24 \%$ and $32 \%$ of the study period in Mutisya Mango Farm and KARI Katumani stations respectively during the MAM seasons. The OND seasons had $28 \%$ and $32 \%$ of the study period in Mutisya Mango Farm and KARI Katumani stations experiencing dry climatic conditions. On average, this translates to a drought cycle of once in every 3 years.

\subsection{Rainfall Variation}

The amount of rainfall received in a given area varies from year-to-year and from season-to-season. The variations increase with decrease in rainfall amount. High variability characterizes the arid and semi-arid regions where rainfall is low and erratic. The coefficient of variation $(C V)$ was used to establish variations in annual and seasonal rainfall. $C V$ is simply obtained by dividing the standard deviation by the long-term mean and it is expressed as a percentage.

$$
c v=\frac{\sigma}{\bar{x}} * 100
$$

The KARI Katumani station had a $c v$ of $24 \%$. This implies that in $67 \%$ of the period under study, rainfall varied by $+/-24 \%$ from its long-term mean of $730.1 \mathrm{~mm}$. The $C V$ for Mutisya Mango Farm station was $40 \%$. That is, in $67 \%$ of the study period, rainfall varied by $+/-40 \%$ from the long-term mean of $611.0 \mathrm{~mm}$. Areas around KARI Katumani station therefore had more dependable rainfall than areas around Mutisya Mango Farm. The rainfall estimates farmers made in a given year were therefore more reliable in KARI Katumani than around Mutisya Mango Farm station. Farmers used the average rainfall more reliably in KARI Katumani area. The variations in rainfall amounts were higher during both MAM and OND rainfall seasons. The $C V$ for of KARI Katumani was $42 \%$ and $41 \%$ for MAM and OND rainfall season respectively and $39 \%$ and $54 \%$ for Mutisya Mango Farm in that order.

\subsection{Exceedance Probability}

The probability of exceedance explains the likelihood of specific rainfall amount or higher will occur in a given year. In the study, the probability of exceedance was expressed as a percentage using WMO formula as adopted by [8].

$$
p=\frac{r-0.44}{n+0.12} * 100
$$


The maximum rainfall amounts recorded in the two rainfall stations were $1154.6 \mathrm{~mm}$ in 2006 in KARI Katumani Station and 1252.9mm in 1997 in Mutisya Mango Farm station (Table 1). The probability of exceeding these maxima was $20 \%$. In other words, 2 in every 10 years received rainfall that exceeded the maxima. The probability of exceeding above normal rainfall (see Figures 5 \& 6) was $46 \%$ and $42 \%$ for the two stations respectively. That is, about 4 to 5 in every 10 years received rainfall that exceeded above normal rainfall. The probability that KARI Katumani and Mutisya Mango Farm stations experienced drought was 26\% translating to a drought frequency of once in every 4 years. Like for annual rainfall, the probability of exceeding the maximum seasonal rainfall in MAM and OND was $20 \%$ in both the stations. In KARI Katumani station, the probability of exceeding above normal rainfall (see Fig 7 \& 8) was $26 \%$ for MAM and 14\% for OND season (Table 2). The probability of not exceeding normal rainfall was $34 \%$ for each of MAM and OND seasons. In Mutisya Mango Farm station, the probability of exceeding above normal rainfall (see Fig 9 \& 10) was $22 \%$ for each of MAM and OND season. The probability of not exceeding normal rainfall was $26 \%$ and $30 \%$ for MAM and OND seasons respectively. Frequency of drought in KARI Katumani station was relatively higher compared to Mutisya Mango Farm station. Averagely, the probability of seasonal not exceeding normal rainfall was $31 \%$ translating to a drought frequency of once in every 3 years.

Table 1: Exceedance probability for annual rainfall in KARI Katumani and Mutisya Mango Farm stations

\begin{tabular}{|c|c|c|c|c|c|c|}
\hline \multirow[b]{2}{*}{ Year } & \multicolumn{2}{|c|}{ KARI Katumani } & \multicolumn{2}{|c|}{ Mutisya Mango Farm } & \multirow[b]{2}{*}{$\begin{array}{c}\text { rank } \\
\text { (r) }\end{array}$} & \multirow[b]{2}{*}{$\begin{array}{c}\text { Probability of } \\
\text { exceedance }\end{array}$} \\
\hline & $\begin{array}{l}\text { Annual } \\
\text { rainfall } \\
\text { amount }\end{array}$ & $\begin{array}{l}\text { Ranked } \\
\text { rainfall } \\
\text { amount }\end{array}$ & $\begin{array}{l}\text { Annual } \\
\text { rainfall } \\
\text { amount }\end{array}$ & $\begin{array}{l}\text { Ranked } \\
\text { rainfall } \\
\text { amount }\end{array}$ & & \\
\hline 1990 & 926.8 & 1154.6 & 856.5 & 1252.9 & 1 & 0.02 \\
\hline 1991 & 563.5 & 1106.6 & 676.1 & 1179.7 & 2 & 0.06 \\
\hline 1992 & 591.8 & 926.8 & 677.4 & 856.5 & 3 & 0.10 \\
\hline 1993 & 785.6 & 881.6 & 506.6 & 816.4 & 4 & 0.14 \\
\hline 1994 & 881.6 & 872.9 & 750.8 & 789.4 & 5 & 0.18 \\
\hline 1995 & 595.7 & 858.7 & 702.0 & 750.8 & 6 & 0.22 \\
\hline 1996 & 505.4 & 828.1 & 789.4 & 722.2 & 7 & 0.26 \\
\hline 1997 & 756.6 & 810.5 & 1252.9 & 720.9 & 8 & 0.30 \\
\hline 1998 & 1106.6 & 785.6 & 1179.7 & 702.0 & 9 & 0.34 \\
\hline 1999 & 661.3 & 780.8 & 720.9 & 677.4 & 10 & 0.38 \\
\hline 2000 & 477.6 & 764.9 & 491.0 & 676.1 & 11 & 0.42 \\
\hline 2001 & 692.7 & 756.6 & 483.2 & 588.3 & 12 & 0.46 \\
\hline 2002 & 780.8 & 692.7 & 816.4 & 565.7 & 13 & 0.50 \\
\hline 2003 & 674.8 & 677.7 & 588.3 & 544.8 & 14 & 0.54 \\
\hline 2004 & 660 & 674.8 & 485.7 & 506.6 & 15 & 0.58 \\
\hline 2005 & 614.8 & 661.3 & 291.5 & 491.0 & 16 & 0.62 \\
\hline 2006 & 1154.6 & 660 & 722.2 & 485.7 & 17 & 0.66 \\
\hline 2007 & 764.9 & 614.8 & 389.1 & 484.6 & 18 & 0.70 \\
\hline 2008 & 519 & 595.7 & 308.8 & 483.2 & 19 & 0.74 \\
\hline 2009 & 490 & 591.8 & 331.2 & 389.1 & 20 & 0.78 \\
\hline 2010 & 858.7 & 563.5 & 484.6 & 338.3 & 21 & 0.82 \\
\hline 2011 & 677.7 & 519 & 323.0 & 331.2 & 22 & 0.86 \\
\hline 2012 & 872.9 & 505.4 & 544.8 & 323.0 & 23 & 0.90 \\
\hline 2013 & 810.5 & 490 & 338.3 & 308.8 & 24 & 0.94 \\
\hline 2014 & 828.1 & 477.6 & 565.7 & 291.5 & 25 & 0.98 \\
\hline
\end{tabular}

Table 2: Exceedance probability for seasonal rainfall in KARI Katumani and Mutisya Mango Farm stations

\begin{tabular}{|c|c|c|c|c|c|c|c|c|c|}
\hline & \multicolumn{4}{|c|}{ KARI Katumani } & \multicolumn{3}{c|}{ Mutisya Mango Farm } & \multirow{2}{*}{ Probability } \\
of \\
\end{tabular}


An Analysis of Rainfall Characteristics in Machakos County, Kenya

\begin{tabular}{|l|c|c|c|c|c|c|c|c|c|c|}
\hline 1996 & 212.9 & 402.2 & 189.2 & 329.3 & 277 & 267.9 & 431.2 & 388.0 & 7 & 0.26 \\
\hline 1997 & 276 & 390.6 & 470.8 & 322.7 & 399 & 248.5 & 834.0 & 342.0 & 8 & 0.30 \\
\hline 1998 & 403.6 & 387.6 & 129.7 & 322.6 & 321.7 & 238.5 & 144.6 & 331.0 & 9 & 0.34 \\
\hline 1999 & 244.6 & 367.3 & 386.2 & 318.7 & 209.2 & 223 & 449.5 & 287.0 & 10 & 0.38 \\
\hline 2000 & 137.4 & 335.5 & 322.6 & 315.2 & 174.4 & 213 & 252.4 & 283.0 & 11 & 0.42 \\
\hline 2001 & 217.2 & 276 & 219.9 & 310.9 & 173.7 & 209.2 & 242.0 & 260.0 & 12 & 0.46 \\
\hline 2002 & 335.5 & 264.4 & 347.9 & 298.4 & 297.5 & 194.2 & 418.7 & 255.4 & 13 & 0.50 \\
\hline 2003 & 402.2 & 248.6 & 176 & 270.7 & 344 & 187.4 & 228.6 & 252.4 & 14 & 0.54 \\
\hline 2004 & 264.4 & 244.6 & 298.4 & 237.7 & 168.8 & 180.3 & 255.4 & 242.0 & 15 & 0.58 \\
\hline 2005 & 367.3 & 233.7 & 214.6 & 228.9 & 180.3 & 174.4 & 74.0 & 228.6 & 16 & 0.62 \\
\hline 2006 & 387.6 & 232.7 & 660.4 & 219.9 & 248.5 & 173.7 & 404.0 & 198.1 & 17 & 0.66 \\
\hline 2007 & 390.6 & 217.2 & 228.9 & 214.6 & 120.9 & 168.8 & 196.9 & 196.9 & 18 & 0.70 \\
\hline 2008 & 206.8 & 212.9 & 176.6 & 210.8 & 93.9 & 160 & 153.2 & 176.5 & 19 & 0.74 \\
\hline 2009 & 178.3 & 206.8 & 204.8 & 208.5 & 130.7 & 153.2 & 172.1 & 172.1 & 20 & 0.78 \\
\hline 2010 & 460.8 & 183.6 & 270.7 & 204.8 & 187.4 & 130.7 & 176.5 & 153.2 & 21 & 0.82 \\
\hline 2011 & 248.6 & 181.5 & 310.9 & 189.2 & 160 & 120.9 & 131.4 & 144.6 & 22 & 0.86 \\
\hline 2012 & 493.3 & 178.3 & 315.2 & 176.6 & 117.6 & 118 & 287.0 & 135.4 & 23 & 0.90 \\
\hline 2013 & 515.1 & 137.4 & 210.8 & 176 & 153.2 & 117.6 & 135.4 & 131.4 & 24 & 0.94 \\
\hline 2014 & 545.2 & 95.4 & 208.5 & 129.7 & 194.2 & 93.9 & 198.1 & 74.0 & 25 & 0.98 \\
\hline
\end{tabular}

\subsection{Time Series Analysis}

The Mann-Kendall (MK) trend test was used to detect whether there was trends in time series for both annual and seasonal rainfall. The test is highly recommended for climatological studies since it does not require normally distributed data [9]. The null hypothesis, H0, is that the rainfall data in a time series had no trend while the alternate hypothesis, H1, is that there was a trend in the series. Addinsoft's XLSTAT Software was used to calculate the statistical MK test. The $95 \%$ confidence level was adopted for testing the H0. Where the p value was less than alpha $=0.05$, the $\mathrm{H} 0$ was rejected indicating that there was a trend in time series of rainfall data. Where the $\mathrm{p}$ value was greater than 0.05 , the $\mathrm{H} 0$ was accepted indicating that the trend was not detected. The MK test was applied for KARI Katumani and Mutisya Mango Farm stations and the result shown in Table 3.

Table 3: MK time series trend analysis for annual and seasonal rainfall

\begin{tabular}{|c|c|c|c|c|c|}
\hline Station & $\begin{array}{c}\text { Mann Kendall Statistic } \\
\text { (S) }\end{array}$ & Kendall's tau & $\operatorname{Var}(\mathbf{S})$ & $\begin{array}{l}\text { p-value (one- } \\
\text { tailed) }\end{array}$ & Alpha \\
\hline \multicolumn{6}{|c|}{ Annual rainfall } \\
\hline KARI Katumani & 28.000 & 0.093 & 0.000 & 0.749 & 0.05 \\
\hline Mutisya Mango Farm & -120.000 & -0.400 & 0.000 & 0.002 & 0.05 \\
\hline \multicolumn{6}{|c|}{ Seasonal rainfall } \\
\hline KARI Katumani (OND) & -70.000 & -0.233 & 0.000 & 0.054 & 0.05 \\
\hline KARI Katumani (MAM) & 112.000 & 0.373 & 0.000 & 0.996 & 0.05 \\
\hline Mutisya Mango Farm (OND) & -120.000 & -0.400 & 0.000 & 0.002 & 0.05 \\
\hline Mutisya Mango Farm (MAM) & -110.000 & -0.367 & 0.000 & 0.005 & 0.05 \\
\hline
\end{tabular}

Data in Table 3 reveals that the $p$ value was greater than the alpha (0.05) for KARI Katumani and lesser for Mutisya Mango Farm. Therefore, the H0 was accepted for KARI Katumani station and rejected for Mutisya Mango Farm station. No trend in time series of annual rainfall data was detected for KARI Katumani station. On the other hand, a negative trend in time series of annual rainfall was detected in Mutisya Mango Farm station. The $p$-value was greater than the alpha (0.05) for KARI Katumani MAM and OND seasons and lesser in both in Mutisya Mango Farm station. This implies that no trend in time series of seasonal rainfall data was detected for KARI Katumani MAM and OND seasons but negative trends in time series of annual rainfall were detected for both MAM and OND seasons in Mutisya Mango Farm station. 


\section{Conclusion}

Machakos County exhibited varying rainfall characteristic. Analysis of annual rainfall showed high occurrence of normal to wet climatic conditions and low drought conditions. A drought cycle of 4 years was established. Concentration of annual rainfall was moderate (PCI of $14.4-15$ ) where rainfall was distributed in approximately $75 \%$ of the year. Although, like for annual rainfall normal to wet climatic conditions during the seasonal rains predominated, drought frequency was higher. A drought cycle of 3 years was established during the MAM and OND rainfall seasons. The MAM season had a uniform concentration (PCI of 8.8 - 9.2) of rainfall over the seasons while the OND season had moderate concentration (PCI of 10.5). This concentration magnitude was adequate for rain-fed agriculture.

Based on the adequacy of occurrence of normal to wet climatic conditions and rainfall concentration over the study period, variation in rainfall amount during normal and wet climatic condition was the key parameter influencing rain-fed agricultural activities. Annual rainfall varied from $+/-24 \%$ to $+/-40 \%$ from the long-term mean in KARI Katumani and Mutisya Mango Farm stations respectively. Variations were even higher during seasonal rainfall affecting growing calendar. The CV for of KARI Katumani was $42 \%$ and $41 \%$ for MAM and OND rainfall season respectively and 39\% and 54\% for Mutisya Mango Farm in that order. The negative annual and seasonal rainfall trends compounded with high variability in Mutisya Mango Farm Station was an indicator that rainfall in the areas around the station was gradually becoming less dependable. The negative trend makes it difficult for farmers to predict rainfall performance. On the other hand, while rainfall variability was high in KARI Katumani, lack of trends in time series in annual and seasonal rains made rainfall more dependable. It was therefore easy for farmers to use the rainfall mean to predict rainfall performance and to plan their agricultural activities.

\section{References}

[1] FAO (2016) Agriculture in Sub-Saharan Africa: Prospects and challenges for the next decade. OECD-FAO Agricultural Outlook 2016-2025.

[2] WMO (2015) The Climate in Africa: 2013. World Meteorological Organization (WMO) Geneva, Switzerland

[3] Alam, Md. M., Toriman, M. E., Siwar, C. and Talib, B. (2010) Rainfall Variation and Changing Pattern of Agricultural Cycle. American Journal of Environmental Sciences 7 (1): 82-89, 2011 Science Publications. Available online at: http://thescipub.com/PDF/ajessp.2011.82.89.pdf

[4] Bibi, U. M., Kaduk, J. and Balzter, H. (2014) Spatial-Temporal Variation and Prediction of Rainfall in Northeastern Nigeria. Climate issue 2. doi:10.3390/cli2030206. Available online at: www.mdpi.com/journal/climate

[5] Tierney, J. E., Ummenhofer, C. C. and Menocal, P. B. (2015) Past and future rainfall in the Horn of Africa. In Science Advances Vol. 1 (9). DOI: 10.1126/sciadv.1500682

[6] Huho, J. M., Ngaira, J. K. W., Ogindo, H. O. and Masayi, N. (2012) The changing rainfall pattern and the associated impacts on subsistence agriculture in Laikipia East District, Kenya. Journal of Geography and Regional Planning Vol. 5(7), pp. 198-206. DOI: 10.5897/JGRP12.018. Available online at http://www.academicjournals.org/JGRP

[7] Oliver, J. E. (1980) Monthly precipitation distribution: a comparative index. In Professional. Geography. DOI: 10.1111/j.00330124.1980.00300.x

[8] Raes, D (2004) Frequency analysis of rainfall data. International Centre for Theoretical Physics. Leuven, Belgium

[9] Karmeshu, N. (2012). Trend Detection in Annual Temperature \& Precipitation using the Mann Kendall Test: A Case Study to Assess Climate Change on Select States in the Northeastern United States" Master of Environmental Studies Capstone Projects. 47. http://repository.upenn.edu/mes_capstones/47 